\title{
Comparison and Validation of Traditional and 3D Scanning Anthropometric Methods to Measure the Hand
}

\author{
Emily SEIFERT, Linsey A. GRIFFIN* \\ University of Minnesota, St. Paul, (MN), USA \\ https://doi.org/10.15221/20.41
}

\begin{abstract}
Using full-color hand-held three-dimensional scanners allows researchers to gather anthropometric data outside of a lab setting. The ability to gather a broader and more diverse database is essential to the fit and sizing of products. However, full-color hand-held three-dimensional scanning has not been fully validated as a methodology to take accurate measurements for the hand. This study aimed to examine three different tools for collecting anthropometric data for the hand by their precision. The anthropometric methods compared include tools used in traditional anthropometry, such as a smallbone caliper and tape measure and two (2) full-color hand-held three-dimensional scanners (Occipital Structure Sensor and Artec Leo). Twelve (12) three-dimensional hand scans were 3D printed with a Creality CR-10 three-dimensional printer using PLA materials. The three-dimensional scans were a part of a more extensive database, and the chosen scans represented a range of handbreadth measurements. Eight traditional anthropometric measurements, including length, breadth, and circumference, were collected to assess the precision of manual anthropometric measurements compared to digital measurements from the Occipital Structure Sensor and the Artec Leo. The results from this study showed no statistically significant differences between the manual anthropometric measurements and the digital measurements from the Artec Leo. There were limited statistical differences between the manual anthropometric measurements and the digital measurements from the Occipital Structure Sensor. There were limited statistical differences between the digital measurements from the Occipital Structure Sensor and the digital measurements from the Artec Leo. The information provided in this study will benefit the collection of anthropometric data for the hand by researchers. Three-dimensional technology and processes offer more opportunities to collect data for the hand, which will help improve the design of products that interact with the hand.
\end{abstract}

Keywords: 3D Scanning, Comparison, Validation, Hand Anthropometry

\section{Introduction}

Anthropometric data from the hand is used to assist designers and manufacturers in creating products that interact with the hand to improve work efficiency, comfort, and safety [1]. Researchers use various means to collect anthropometric data from the hand, including traditional methods (caliper and tape measure), two-, three-, and four-dimensional scanners. It is imperative that tools used to collect anthropometric data are validated for the specific body part; in this case, the hand, to ensure that the data is reliable.

\subsection{Hand Anthropometric Data}

Simple hand anthropometric data is found in most large anthropometric studies of the body and include hand measurements, such as Hand Breadth, Hand Length, and Hand Circumference. These measurements directly correlate with the measurements frequently used in sizing charts for gloves and other products that interact with the hand [2].

Hand anthropometric data is used to improve the fit and sizing of various products, including gloves. Gloves are used in a wide variety of settings and have many uses ranging from protecting the hand against possible hazards (weather, chemicals, abrasion, cuts, scrapes, and blood/bodily fluids) to protecting delicate objects from the hand's oils, such as artifacts and computer chips.

The gloved hands' performance is substantially affected by the properties of the glove's material and by the fit of the gloves [3]. A tight-fitting glove can constrict finger circulation and may increase the risk of injuries. On the other hand, gloves that fit too loosely hinder the accomplishment of tasks that require fine dexterity and gripping [4]. The use of gloves under either of these conditions is dangerous to the user. It is crucial that designers and manufacturers work with robust anthropometric data to create products that fit the user better. 


\subsection{Tools for Anthropometric Measurement for the Hand}

Researchers rely on anthropometric data provided by measurement tools to assist in the fit and sizing of products that interact with the hand. Many different measurement tools are available to capture anthropometric data from the hand. This study focuses on three different tools: traditional anthropometric tools (caliper and tape measure) and two (2) full-color hand-held three-dimensional scanners (Occipital Structure Sensor and Artec Leo).

Traditional methods include the use of calipers and tape measures. This method has been used extensively to collect anthropometric data from the hand [5, 6, 7, 8, 9]. Calipers and tape measures capture physical measurements directly from the body. Calipers collect linear measurements (such as length and breadth), and tape measures collect surface measurements (such as circumference).

The use of three-dimensional scanning has become an increasingly viable method for capturing anthropometric data of the hand. Several stationary three-dimensional scanners have been validated to collect anthropometric data from the hand [10,11]. However, the Occipital Structure Sensor and Artec Leo, both full-color hand-held scanners, have not been validated to collect anthropometric hand data. When using any tool for collecting anthropometric data, it is vital to test its reliability and validity. A measurement tool's reliability and validity can influence the measurements collected and the interpretation of the results [12]. In order to ensure that designers and manufacturers have accurate anthropometric data, new tools must be validated.

\subsection{Purpose}

The purpose of this study was to examine the precision of three different tools for collecting anthropometric data of the hand. The anthropometric methods compared in this study include traditional anthropometric tools (caliper and tape measure) and two (2) full-color hand-held three-dimensional scanners (Occipital Structure Sensor and Artec Leo).

\section{Method Development}

\subsection{Overview}

The method development for this study includes information on the participants, tools, landmarking, measurements used, and data analysis. These methods were tested previously in a pilot study with one (1) test hand model to verify their outcomes.

\subsection{Participants}

Twelve (12) three-dimensional hand scans were printed with a Creality CR-10 three-dimensional printer using white PLA materials (see Fig.1). The twelve (12) three-dimensional hand scans selected were part of a more extensive database taken by the Human Dimensioning Lab at the University of Minnesota. Participants for this database were recruited at the 2019 Minnesota State Fair through the Driven to Discover (D2D) research program. The database included basic demographic information and manual hand breadth data for each participant. Inclusion for the study was based on a stratified sample of participants representing a distribution of $95 \%$ to $5 \%$ measurements of hand breadth.

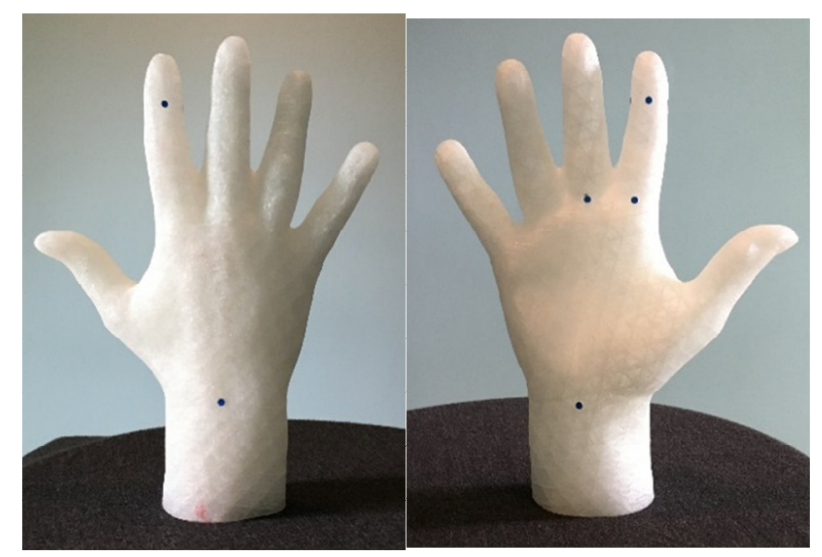

Fig. 1. Landmarked three-dimensional printed hand.

Hand Breadth was determined based on the summary statistics provided by the ANSUR II database [9]. The final demographics for the participants represent a range of Hand Breadth chosen to cover over $95 \%$ to under $5 \%$. This study included six (6) male and six (6) female participants between the ages of 16 and 64 of Caucasian and Asian descent. 


\subsection{Tools}

This study examines three different tools for collecting anthropometric data: traditional methods (caliper and tape measure), the Occipital Structure Sensor, and the Artec Leo.

Traditional methods include the use of calipers and tape measures. A large bone caliper, small bone caliper, and tape measure were selected as tools. Traditional method tool specifications are found in Table 1.

Table 1. Tools for the traditional method (caliper and tape measure).

\begin{tabular}{|c|c|c|c|}
\hline $\begin{array}{c}\text { Specification/ } \\
\text { Tool }\end{array}$ & Cescorf Large Bone Caliper & Cescorf Small Bone Caliper & $\begin{array}{c}\text { Lufkin Executive Diameter } \\
\text { Metric Tape Measure } \\
\text { (W606PM) }\end{array}$ \\
\hline Image & 600 millimeters & 180 millimeters & 2 meters \\
\hline Range & Hand Length and Palm Length & $\begin{array}{c}\text { Hand Breadth, Index Finger } \\
\text { Length, and Index Finger } \\
\text { Breadth }\end{array}$ & $\begin{array}{c}\text { Wrist Circumference, Hand } \\
\text { Circumference, and Index } \\
\text { Finger Circumference }\end{array}$ \\
\hline Used for
\end{tabular}

Two (2) full-color hand-held three-dimensional scanners were selected to be validated. The Occipital Structure Sensor is a full-color hand-held three-dimensional scanner that works with an iPad. It can capture anatomical scans of the hand in roughly 1.5 to 2.5 minutes. The Artec Leo is a wireless scanner that offers automatic onboarding processing and can capture anatomical scans in roughly 1 minute.

Information on the tools chosen for this method of data collection is located in Table 2. This table's information has been organized according to the 3D Hand Scanning Attributes Framework (3DHSAF) by Sokolowski, Griffin, \& Chandrasekhar (2018) [13]. This framework provides researchers with a checklist of critical three-dimensional scanner attributes needed to collect appropriate hand data, including color capture, file saving, hand-held compatibility, location of the scanner vendor, scanning envelope, scanner price, scan resolution, scanner size, scanner weight, and time to scan.

Table 2. Comparison of specification for the full-color hand-held three-dimensional scanners.

\begin{tabular}{|c|c|c|}
\hline Specification/Tool & Occipital Structure Sensor & Artec Leo \\
\hline \multicolumn{3}{|l|}{ Image } \\
\hline Color/Texture Capture & Yes & Yes \\
\hline File Saving & SDK/OBJ/STL & $\begin{array}{c}\text { OBJ/PLY/WRL/STL/AOP/ASCII/PTX/E } \\
\text { 57/XYZRGB }\end{array}$ \\
\hline Hand-held Compatibility & Yes & Yes \\
\hline Scanner Vendor Location & $\begin{array}{c}\text { San Francisco, California \& Boulder, } \\
\text { Colorado, USA }\end{array}$ & $\begin{array}{l}\text { Luxembourg, subsidiaries in Palo Alto, } \\
\text { California, USA, and Moscow, Russia }\end{array}$ \\
\hline Scanner Envelope & $400 \mathrm{~mm}$ high by $3500 \mathrm{~mm}$ wide & 244 by $142 \mathrm{~mm}$ \\
\hline Scanner Price & $\$ 527.00$ & $\$ 25,800.00$ \\
\hline Scanner Resolution & VGA ( 640 by 480 pixels) & 2.3 megapixels \\
\hline Scanner Size & $\begin{array}{c}119.9 \mathrm{~mm} \mathrm{~L} \text { by } 29 \mathrm{~mm} \mathrm{H} \text { by } 28 \mathrm{~mm} \mathrm{~W} \\
\text { (affixes to an iPad) }\end{array}$ & $231 \mathrm{~mm} \mathrm{H}$ by $162 \mathrm{~mm} \mathrm{D}$ by $230 \mathrm{~mm} \mathrm{~W}$ \\
\hline Scan Technology & Structured Light & Structured Light (VCSEL) \\
\hline Scanner Weight & $0.1 \mathrm{~kg}$ plus iPad & $2.6 \mathrm{kgs}(5.7 \mathrm{lbs})$ \\
\hline Time to Scan & Approximately 1.5 to 2.5 minutes & Approximate 1 minute \\
\hline
\end{tabular}




\subsection{Landmarking}

Fourteen (14) total landmarks were placed on the three-dimensional printed hands using blue 0.125" diameter circular dot stickers (see Fig. 1). The landmarking procedures are adapted from Griffin, Sokolowski, Lee, Seifert, Kim, \& Carufel (2018) [14], and locations were identified through literature and previous anthropometric studies [5, 6, 7, 8, 9]. Landmarks are used to ensure the measurement's accuracy so that it is taken from the same location [15]. Landmarks were placed at anatomical locations on the three-dimensional print hand (see Table 3).

Table 3. Landmark Locations and Definitions.

\begin{tabular}{|l|l|l|}
\hline$\#$ & Landmark Location & Description \\
\hline 1 & Fingertip of Digit 2 & The center of the distal tip of digit 2. \\
\hline 2 & Fingertip of Digit 3 & The center of the distal tip of digit 3. \\
\hline 3 & $\begin{array}{l}\text { Distal Interphalangeal Joint of } \\
\text { Digit 2 (Dorsal Side) }\end{array}$ & The center of the dorsal side of the Distal Interphalangeal Joint of digit 2. \\
\hline 5 & $\begin{array}{l}\text { Distal Interphalangeal Joint of } \\
\text { Digit 2 (Palmar Side) }\end{array}$ & The center of the palmar side of the Distal Interphalangeal Joint of digit 2. \\
\hline 6 & $\begin{array}{l}\text { Distal Interphalangeal Joint of } \\
\text { Digit 2 (Medial Side) }\end{array}$ & The center of the medial side of the Distal Interphalangeal Joint of digit 2. \\
\hline 7 & Base of Digit 2 & The center of the crease at the base of digit 2 on the palmar side. \\
\hline 8 & Base of Digit 3 & The center of the crease at the base of digit 3 on the palmar side. \\
\hline 9 & Metacarpal 2 & $\begin{array}{l}\text { The center of the lateral point of the Metacarpal Phalangeal Joint } 2 \text { (at the } \\
\text { base of digit 2, on the outer edge of the three-dimensional printed hand). }\end{array}$ \\
\hline 10 & Metacarpal 5 & $\begin{array}{l}\text { The center of the medial point of the Metacarpal Phalangeal Joint } 5 \text { (at the } \\
\text { base of digit 5, on the outer edge of the three-dimensional printed hand). }\end{array}$ \\
\hline 11 & Radial Styloid (Lateral Side) & The inferior point of the bottom of the radius. \\
\hline 12 & Radial Styloid (Dorsal Side) & $\begin{array}{l}\text { Using the inferior point of the bottom of the radius as reference, the } \\
\text { extension of this landmark around the wrist to the dorsal side. }\end{array}$ \\
\hline 13 & Radial Styloid (Palmar Side) & $\begin{array}{l}\text { Using the inferior point of the bottom of the radius as reference, the } \\
\text { extension of this landmark around the wrist to the palmar side. }\end{array}$ \\
\hline 14 & Radial Styloid (Medial Side) & $\begin{array}{l}\text { Using the inferior point of the bottom of the radius as reference, the } \\
\text { extension of this landmark around the wrist to the medial side. }\end{array}$ \\
\hline
\end{tabular}

\subsection{Measurement}

Eight defined measuring distances were obtained using traditional methods (caliper and tape measure) and digital measuring using Anthroscan from the scans provided by the two (2) three-dimensional scanners (the Occipital Structure Sensor and the Artec Leo) for each participant (see Table 4). The measurements in this table were identified through literature and previous anthropometric studies $[5,6$, $7,8,9,16]$.

\subsection{Analysis of Data}

The defined measurements were first taken on the three-dimensional hand manually using traditional methods (caliper and tape measure).

Scans were then taken using the Occipital Structure Sensor and the Artec Leo.

The scans from the Occipital Structure Sensor go through automatic processing in the SDK scanning application software. The files were then taken into Meshmixer for minimal editing to delete the scanning platform.

The Artec Leo's scans are exported from the Artec Leo and imported into Artec Studio 14 Professional Software. Artec Studio 14 Professional Software is then used for manual processing and minimal editing to delete the scanning platform.

Once editing was complete, the scans were measured digitally using Anthroscan, an anthropometric measurement software by Human Solutions. 
The difference in defined measuring distances between landmarks on the dominant hand using the traditional methods (caliper and tape measure), Occipital Structure Sensor, and Artec Leo were evaluated to determine if there are statistically significant differences with a confidence interval of $95 \%$. This data's statistical analysis includes descriptive statistics for each measurement from each tool. The significance of the differences among the different means of each hand measurement from the three methods was reported using $p$-values derived from paired t-tests. This method was used to compare the traditional methods (caliper and tape measure) to the Occipital Structure Sensor, traditional methods (caliper and tape measure) to the Artec Leo, and the Artec Leo to the Occipital Structure Sensor.

Table 4. Defined Measurements

\begin{tabular}{|l|l|}
\hline Measurement Name & Measurement Definition \\
\hline Hand Breadth & $\begin{array}{l}\text { The distance from the Metacarpal 2 landmark (located on the lateral side of digit 2) to } \\
\text { the Metacarpal 5 landmark (located on the medial side of digit 5), measured } \\
\text { perpendicular to the long axis of digit 3. }\end{array}$ \\
\hline Hand Length & $\begin{array}{l}\text { The distance from the fingertip of digit 3 landmark to the landmark located on the } \\
\text { Radial Styloid (Palmar Side). }\end{array}$ \\
\hline Palm Length & $\begin{array}{l}\text { The distance between the landmark located at the base of digit 3 landmark to the } \\
\text { landmark located on the Radial Styloid (Palmar Side). }\end{array}$ \\
\hline Index Finger Length & $\begin{array}{l}\text { The distance from the landmark located on the fingertip of digit 2 to the landmark } \\
\text { located on the base of digit 2. }\end{array}$ \\
\hline Index Finger Breadth & $\begin{array}{l}\text { The distance between the landmark located on the lateral side of the Distal } \\
\text { Interphalangeal Joint to the landmark located on the medial side of the Distal } \\
\text { Interphalangeal Joint. }\end{array}$ \\
\hline Wrist Circumference & $\begin{array}{l}\text { The circumference of the wrist is measured by passing over the four landmarks } \\
\text { located on the Radial Styloid around the wrist (Dorsal, Palmar, and Medial Side). }\end{array}$ \\
\hline Hand Circumference & $\begin{array}{l}\text { The circumference of the hand is measured over the landmarks at Metacarpal 2 and } \\
\text { Metacarpal 5. }\end{array}$ \\
\hline Index Finger \\
Circumference & $\begin{array}{l}\text { The Circumference of the Index Finger is measured by passing over the landmarks } \\
\text { located on the Distal Interphalangeal Joint of digit 2 (Dorsal, Palmar, Lateral, and } \\
\text { Medial Side). }\end{array}$ \\
\hline
\end{tabular}

\section{Results}

The results from this study (see Table 5) showed no statistically significant differences between the traditional methods (caliper and tape measure) and the Artec Leo.

There were also no statistically significant differences found for Hand Breadth, Hand Length, Palm Length, Index Finger Breadth, Wrist Circumference, and Hand Circumference between the traditional methods (caliper and tape measure) and the Occipital Structure Sensor and between the Artec Leo and the Occipital Structure Sensor.

However, there were statistically significant differences found at two measurement locations, the Index Finger Length and the Index Finger Circumference.

At the Index Finger Length, statistically significant differences occurred between traditional methods (caliper and tape measure) $(M=7.12, S D=0.3)$ and the Occipital Structure Sensor $(M=6.55, S D=$ 0.41 ) with a $p$-value of 0.0007993 and between the Artec Leo $(M=6.98, S D=0.35)$ and the Occipital Structure Sensor $(M=6.55, S D=0.41)$ with a $p$-value of 0.01157 .

At the Index Finger Circumference, statistically significant differences occurred between traditional methods (caliper and tape measure) $(M=5.63, S D=0.66)$ and Occipital Structure Sensor $(M=4.83$, $\mathrm{SD}=0.57)$ with a $\mathrm{p}$-value of 0.004034 and between the Artec Leo $(\mathrm{M}=5.49, \mathrm{SD}=0.54)$ and the Occipital Structure Sensor $(M=4.83, S D=0.57)$ with a $p$-value of 0.007668 . 
Table 5. Statistical Analysis.

\begin{tabular}{|l|l|l|l|l|l|l|l|l|l|}
\hline & \multicolumn{2}{|c|}{ T } & \multicolumn{3}{c|}{ O } & \multicolumn{3}{c|}{ A } & \multicolumn{3}{c|}{ P-Values from Paired T-tests } \\
\cline { 2 - 11 } & Mean & \multicolumn{1}{|c|}{ SD } & Mean & SD & Mean & SD & T vs O & T vs A & A vs O \\
\hline Hand Breadth & 8.37 & 0.93 & 8.46 & 0.95 & 8.52 & 0.96 & 0.8134 & 0.701 & 0.8825 \\
\hline Hand Length & 18.27 & 0.95 & 17.78 & 1 & 18.18 & 0.92 & 0.2374 & 0.8128 & 0.3299 \\
\hline Palm Length & 10.66 & 0.59 & 10.56 & 0.73 & 10.57 & 0.69 & 0.7157 & 0.7297 & 0.9772 \\
\hline $\begin{array}{l}\text { Index Finger } \\
\text { Length }\end{array}$ & 7.12 & 0.3 & 6.55 & 0.41 & 6.98 & 0.35 & $0.0007993^{\star \star *}$ & 0.3028 & $0.01157^{\star}$ \\
\hline $\begin{array}{l}\text { Index Finger } \\
\text { Breadth }\end{array}$ & 1.89 & 0.17 & 1.73 & 0.23 & 1.92 & 0.25 & 0.05737 & 0.7773 & 0.06248 \\
\hline $\begin{array}{l}\text { Wrist } \\
\text { Circumference }\end{array}$ & 16.62 & 1.81 & 16.43 & 1.89 & 16.49 & 1.71 & 0.8018 & 0.8543 & 0.9374 \\
\hline $\begin{array}{l}\text { Hand } \\
\text { Circumference }\end{array}$ & 20.27 & 2.31 & 19.43 & 2.31 & 19.91 & 2.23 & 0.3821 & 0.7025 & 0.6074 \\
\hline $\begin{array}{l}\text { Index Finger } \\
\text { Circumference }\end{array}$ & 5.63 & 0.66 & 4.83 & 0.57 & 5.49 & 0.54 & $0.004034^{* *}$ & 0.5712 & $0.007668^{* *}$ \\
\hline
\end{tabular}

$\mathrm{T}=$ Traditional Methods (caliper and tape measure), $\mathrm{O}=$ Occipital Structure Sensor, $\mathrm{A}=$ Artec Leo *Significant at the .05 level

** Significant at the .01 level

*** Significant at the .005 level

\section{Discussion and Conclusion}

\subsection{Overview}

This study shows that the hand anthropometric measurements from the Artec Leo scanner are comparable to those collected using traditional methods (caliper and tape measure). These results show that the Artec Leo is a valid tool for use in further anthropometric hand data collection.

This study shows promising results for using the Occipital Structure Sensor for the collection of anthropometric data for the hand. The Occipital Structure Sensor was able to collect most of the measurements without a statistically significant difference. The statistically significant measurements obtained by the Occipital Structure Sensor when compared to both the traditional method (caliper and tape measure) and the Artec Leo show a need for more research in order to determine why measurement differences occurred at those locations in order to validate its use for those measurements.

Three-dimensional hand scanning offers researchers, designers, and engineers value beyond measurement precision. The ability to travel with the scanning devices and the fast speed of capture could provide researchers with the ability to build expansive databases of diverse populations. The ability to move around the hand and capture it in its entirety also could increase the possibility of the inclusion of functional hand scanning positions, which have not been seen in other databases. The inclusion of three-dimensional modeling in anthropometric data collection also opens the door for the use of the models taken within the design process.

\subsection{Limitations and Future Research}

There is a visual component to three-dimensional hand scanning, which is not widely discussed in literature. Researchers must ensure that the mesh surface of every three-dimensional hand scan is clean and represents an accurate model of the hand. Dunbar \& Chapates [17] defined the "best" surface mesh for hand scans as one that is free of stray points, uniform in mesh size, free of any artificial "webbing" in between the fingers, and free of errors in mapping the 2D color texture on the surface. This visual analysis has yet to be quantified. A visual analysis in future studies could assist in confirming that the scans used are of sufficient quality for measuring or be used to explain any issues that occur within the results of the study.

The use of models has been used in previous studies $[10,11,17]$ to assist in minimizing possible inconsistencies that occur when using human hands. However, understanding any change to the process and methods that may occur using human hands is vital when considering using these tools for hand anthropometric database collection. Future studies should test these methods with the use of human subjects. 
Future studies should also expand the sample size to include a more diverse population, as well as examine the hand in various functional scanning positions.

\subsection{Implications and Conclusion}

The information provided in the study will benefit the collection of anthropometric data for the hand by researchers. This study shows that the results provided by the Artec Leo scanner are comparable to those collected using traditional methods (caliper and tape measure) and validate the Artec Leo for use in further anthropometric data collection for the hand. This study shows promising results for using the Occipital Structure Sensor for the collection of anthropometric data for the hand, with exception to the Index Finger Length and Index Finger Circumference. The validation of full-color hand-held threedimensional scanning tools leads to more opportunities to collect data, which will impact future product innovations for the hand.

\section{References}

[1] M. Vergara, M. J. Agost, and V. Gracia- Ibáñez, "Dorsal and palmar aspect dimensions of hand anthropometry for designing hand tools and protections," Human Factors and Ergonomics in Manufacturing \& Service Industries, vol. 28, no. 1, pp. 17-28, 2018, https://doi.org/10.1002/hfm.20714.

[2] O. Kwon, K. Jung, H. You, \& H.E. Kim, "Determination of key dimensions for a glove sizing system by analyzing the relationships between hand dimensions," Applied Ergonomics, vol. 40, no. 4, pp. 762-766, 2009, https://doi.org/10.1016/j.apergo.2008.07.003.

[3] P. R. M. Jones and M. Rioux, "Three-dimensional Surface Anthropometry: Applications to the Human Body," Optics and Lasers in Engineering, vol. 28, no. 2, pp. 89-117, Sept. 1997, https://doi.org/10.1016/S0143-8166(97)00006-7.

[4] H. Hsiao, J. Whitestone, T. Y. Kau, and B. Hildreth, "Firefighter Hand Anthropometry and Structural Glove Sizing: A New Perspective," Human Factors, vol. 57, no. 8, pp. 1359-1377, Dec. 2015, https://doi.org/10.1177/0018720815594933.

[5] R. M. White, "Comparative Anthropometry of the Hand," Army Natick Research and Development Labs Ma Clothing Equipment and Materials Engineering Lab, Rep. NATICK/CEMEL-229, 1980.

[6] C.C. Gordon, T. Churchill, C.E. Clauser, B. Bradtmiller, J. T. McConville, I. Tebbetts, and R.A. Walker, "Anthropometric survey of US Army personnel: summary statistics, interim report for 1988," ANTHROPOLOGY RESEARCH PROJECT INC YELLOW SPRINGS OH, 1989.

[7] T. M. Greiner, "Hand anthropometry of US army personnel," ARMY NATICK RESEARCH DEVELOPMENT AND ENGINEERING CENTER MA, Rep. TR-92/011, 1991.

[8] K. M. Robinette, S. Blackwell, H. Daanen, M. Boehmer, and S. Fleming, "Civilian American and European Surface Anthropometry Resource (CAESAR), Final Report. Volume 1. Summary", SYTRONICS INC DAYTON OH, 2002.

[9] C. C. Gordon, C. L. Blackwell, B. Bradtmiller, J. L. Parham, P. Barrientos, S. P. Paquette, B. D. Corner, J. M. Carson, J. C. Venezia, B. M. Rockwell, M. Mucher, and S. Kristensen, "Anthropometric Survey of US Army Personnel: Methods and Summary Statistics," ARMY NATICK SOLDIER RESEARCH DEVELOPMENT AND ENGINEERING CENTER MA, Rep. NATICK/TR-15/007, 2012.

[10] Z. Li, C. C. Chang, P. G. Dempsey, L. Ouyang, and J. Duan, "Validation of a three-dimensional hand scanning and dimension extraction method with dimension data," Ergonomics, vol. 51, no.11, pp. 1672-1692, Nov. 2008, https://doi.org/10.1080/00140130802287280.

[11] A. Yu, K. L. Yick, S. P. Ng, and J. Yip, "2D and 3D anatomical analyses of hand dimensions for custom-made gloves," Applied Ergonomics, vol. 44, no. 3, pp. 381-392, May 2013, https://doi.org/10.1016/j.apergo.2012.10.001.

[12] S. Bragança, P. Arezes, M. Carvalho, and S. P. Ashdown, "Current state of the art and enduring issues in anthropometric data collection," Dyna, vol. 83, no. 197, pp. 22-30, June 2016, https://doi.org/10.15446/dyna.v83n197.57586.

[13] S. L. Sokolowski, L. Griffin, and S. Chandrasekhar, "Current technology landscape for collecting hand anthropometric data," in 9th International Conference and Exhibition on 3D Body Scanning and Processing Technologies, pp. 142-153, Oct. 2018, https://doi.org/10.15221/18.142. 
[14] L. Griffin, S. Sokolowski, H. Lee, E. Seifert, N. Kim, and R. Carufel, "Methods and tools for 3D measurement of hands and feet," in International Conference on Applied Human Factors and Ergonomics, pp. 49-58, Springer, Cham, July 2018, https://doi.org/10.1007/978-3-319-946016 6.

[15] M. Kouchi, "Anthropometric methods for apparel design: Body measurement devices and techniques," in Anthropometry, Apparel Sizing and Design, Woodhead Publishing, Jan. 2014, ch.3, pp. 67-94, https://doi.org/10.1533/9780857096890.1.67.

[16] International Organization for Standardization, "ISO 7250-1: 2017 Basic Human Body Measurements for Technological Design-Part 1: Body Measurement Definitions and Landmarks", 2017.

[17] B. J. Dunbar and P. J. Chapates, "Comparison of 3D photogrammetric and laser hand scans to manual measurement methods for EVA glove fabrication," in 2019 IEEE Aerospace

Conference, pp. 1-11, 2019, https://doi.org/10.1109/AERO.2019.8742197 